\title{
The morphological identification of pathogenic yeasts using carbohydrate media
}

\author{
K. R. JOSHI, D. A. BREMNER, D. N. PARR, AND J. B. GAVIN 1 \\ From the Department of Pathology, University of Auckland, and Microbiology Laboratory, Auckland Public $\vec{\omega}$ \\ Hospital, New Zealand
}

SYNOPSIS Eight isolates of $C$. albicans were used to determine the frequency with which germ tube formation occurred: on rice extract -Tween 80 agar, on its components, and on $1 \%$ bactopeptone $\vec{\infty}$ agar after three $\mathrm{hr}$ at $37^{\circ} \mathrm{C}$; in $0.5 \%$ aqueous solution of various carbohydrates; in various concen-윽 trations of glucose; on 0.5 and $0.1 \%$ glucose agar and on various types of agar alone. Subsequently250 isolates of yeast of the genera Candida, Torulopsis, Trichosporon, Cryptococcus, and Saccharo-ฏ myces, which were obtained from a clinical laboratory, were spread on rice extract -Tween 80 agar and on $0.1 \%$ glucose agar and covered with coverslips. Direct microscopic examination after incubation for three hours at $37^{\circ} \mathrm{C}$ demonstrated germ tube formation by all 140 isolates of $C . \vec{\omega}$ albicans, but by none of the other yeasts. The characteristic features of the pseudomycelia of isolates of Candida and Trichosporon were evident on reexamination after a further 45 to 69 hours at roomi temperature $\left(22^{\circ} \mathrm{C}\right)$. These morphological observations suggested the identity of the isolates of Torulopsis, Cryptococcus, and Saccharomyces but identified virtually all $(98.2 \%)$ of those of the genera which formed pseudomycelia. Of the latter group only four isolates required fermentation and assimilation tests to determine whether they were C. parapsilosis (1) or C. guilliermondii (3).

Candida albicans is the most common pathogenic yeast isolated from clinical specimens. In most laboratories it is identified by its rapid formation of filamentous outgrowths or germ tubes when grown in human serum (Taschdjian, Burchall, and Kozinn, 1960). In studies of the reliability of this germ tube test and of the factors which supposedly mediate this transformation we have demonstrated that it can also occur in trypticase soya broth (Joshi, Bremner, Gavin, Herdson, and Parr, 1973) and in several peptone media (Joshi, Gavin, and Bremner, 1973), and have suggested that a simple solid medium, $1 \%$ bactopeptone in $2 \%$ agar, is most reliable (Joshi and Gavin, 1974).

This paper describes a continuation of these studies in which even simpler media were evaluated and methods evolved to carry out not only the germ tube test, but also the direct examination of the characteristic mycelial morphology of various species of two genera using a single preparation for both examinations.

\footnotetext{
${ }^{1}$ Address for correspondence: Dr J. B. Gavin, Department of Pathology, University of Auckland, Private Bag, Auckland, New Zealand. Received for publication 23 September 1974.
}

\section{Material and Methods}

GERM TUBE PRODUCTION ON RICE EXTRACT MEDIA

Eight isolates of $C$. albicans known to form germ: tubes on bactopeptone agar (Joshi and Gavin, 1974) 3 . and chlamydospores on rice extract -Tween 80 agaro (Difco Laboratories, Detroit, Michigan, USA) were 3 inoculated onto paired preparations of the followingo media: $1 \%$ bactopeptone in rice extract -Tween $80^{\circ}$ medium; $1 \%$ bactopeptone in rice extract medium; $1 \%$ bactopeptone plus $1 \%$-Tween 80 in $2 \%$ agar rice extract -Tween 80 medium; and $1 \%$ bactopeptoneos in $2 \%$ agar. All the media tested in this experimentin were obtained from Difco Laboratories, Detroit, N Michigan, USA.

The lines of inoculation were covered with large coverslips and the preparations incubated at $37^{\circ} \mathrm{C}$ for three $\mathrm{hr}$ at which stage they were examined fores? germ tube formation. Then one preparation of each pair was kept at room temperature $\left(22^{\circ} \mathrm{C}\right)$ and theo other at $37^{\circ} \mathrm{C}$ for another $45 \mathrm{hr}$ at which time al|⿸厂巳一㇉ plates were again examined.

GERM TUBE PRODUCTION IN CARBOHYDRATEO MEDIA

The germ tube test was then performed in 4,2 응 
1 , and $0.5 \%$ sterile solutions of glucose, and in $0.5 \%$ sterile solutions of fructose, galactose, xylose, lactose, maltose, sucrose, mannitol, trehalose, dextrin, glycogen, soluble starch, cellobiose, raffinose, sorbitol, dulcitol, levulose, inulin, inositol, and arabinose. One millilitre aliquots of each of these media were inoculated with fresh cultures of the same eight isolates to provide an initial concentration of $1 \times 10^{6}$ organisms per millilitre. After incubation at $37^{\circ} \mathrm{C}$ for three $\mathrm{hr}$, the percentage of organisms which had developed germ tubes in each preparation was determined from Giemsa-stained smears.

In a subsequent experiment these eight isolates were cultured on 0.5 and $0.1 \%$ glucose (May \& Baker, Dagenham, Essex, England) in $2 \%$ Difco agar (Difco Laboratories, Detroit, Michigan, USA), and also on $2 \%$ Difco agar, $2 \%$ Davis agar (Davis Gelatine NZ, Christchurch, New Zealand), $2 \%$ ion agar no. 2 (Oxoid Ltd, London, England), $2 \%$ Noble agar (Difco Laboratories, Detroit, Michigan, USA), and $2 \%$ agarose (BDH, Chemicals Ltd, Poole, England) alone. Coverslips were placed on the lines of inoculation. The plates were then examined for germ tube formation after incubation at $37^{\circ} \mathrm{C}$ for three $\mathrm{hr}$ and again after another $45 \mathrm{hr}$ at $22^{\circ} \mathrm{C}$.

\section{RELIABILITY OF GLUCOSE AGAR}

Subsequently 140 isolates of C. albicans, and 110 isolates of other yeasts (C. tropicalis $22 ; C$. pseudotropicalis $3 ; C$. krusei 11; C. parapsilosis 33; C. guilliermondii 3; Torulopsis glabrata 31; Trichosporon cutaneum 2; Cryptococcus neoformans 1; Cryptococcus albidus 1; and Saccharomyces cerevisiae 3), which had been obtained from patients from Auckland Public Hospital and which had been identified according to Dolan (1971) were tested. Each isolate was assigned a number based on its order of receipt by the laboratory and was then inoculated onto paired plates of rice extract -Tween 80 and $0.1 \%$ glucose agar medium. To avoid overinoculation a loop containing part of a colony was rubbed onto one side of the medium and then streaked to produce four horizontal and four vertical lines of inoculation which were then covered with sterile coverslips. One of the rice extract plates was kept at room temperature throughout the experiment while the other, together with the glucose agar plate, was incubated at $37^{\circ} \mathrm{C}$ for three $\mathrm{hr}$, then kept at room temperature $\left(22^{\circ} \mathrm{C}\right)$ thereafter. These were then examined directly at magnifications of $\times 100-450$; three $\mathrm{hr}$ and $48 \mathrm{hr}$ after inoculation, and then daily for a further five days.

\section{Results}

The formation of germ tubes and chlamydospores by eight isolates of $C$. albicans on media containing $1 \%$ peptone and/or various components of rice extract -Tween 80 agar are shown in table I. All isolates formed germ tubes within three $\mathrm{hr}$ at $37^{\circ} \mathrm{C}$ on all the five media, and all subsequently formed

\begin{tabular}{|c|c|c|c|}
\hline \multirow[t]{2}{*}{ Medium } & \multirow{2}{*}{$\begin{array}{l}\text { No. with } \\
\text { Germ Tubes } \\
\text { after } 3 \mathrm{Hr} \\
\text { at } 37^{\circ} \mathrm{C}\end{array}$} & \multicolumn{2}{|c|}{$\begin{array}{l}\text { No. with Chlamydospores } \\
\text { afterAnother } 45 \text { Hrat: }\end{array}$} \\
\hline & & $37^{\circ} \mathrm{C}$ & $\begin{array}{l}\text { Room } \\
\text { Temperature }\end{array}$ \\
\hline $\begin{array}{l}1 \% \text { peptone plus rice } \\
\text { extract - Tween } 80 \text { agar } \\
1 \% \text { peptone plus rice }\end{array}$ & 8 & - & 3 \\
\hline $\begin{array}{l}\text { extract agar } \\
1 \% \text { peptone plus } 1 \%-\text { Tweer }\end{array}$ & $\mathbf{n}$ & 一 & 3 \\
\hline $\begin{array}{l}80 \text { and } 2 \% \text { agar } \\
\text { Rice extract -Tween }\end{array}$ & 8 & - & 一 \\
\hline 80 agar & 8 & - & 8 \\
\hline $1 \%$ peptone in $2 \%$ agar & 8 & - & 一 \\
\hline
\end{tabular}

Table I The formation of germ tubes and chlamydospores by eight isolates of $\mathrm{C}$. albicans on media containing various components of rice extract -Tween 80 agar and $1 \%$ peptone

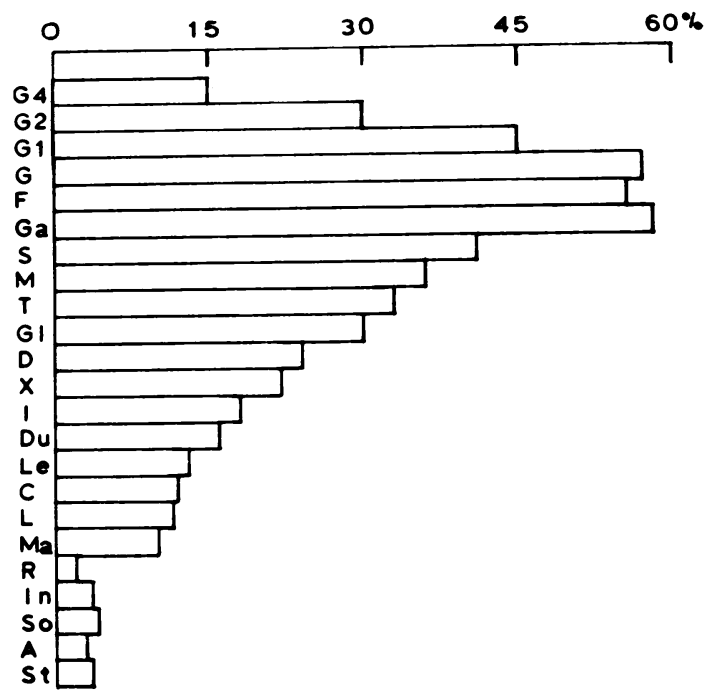

Fig 1 The mean percentage of organisms from eight isolates of $\mathrm{C}$. albicans which formed germ tubes in various $0.5 \%$ carbohydrate media and in various concentrations of glucose.

G4-4\% glucose, G2-2\% glucose, G1-1\% glucose, $G-0.5 \%$ glucose, $F$-fructose, $G a$-galactose, $S$-sucrose, $M$-maltose, $T$-trehalose, $G$-glycogen, $D$-dextrin, $X$-xylose, I-inulin, $\mathrm{Du}$-dulcitol, Le-levulose, Ccellobiose, Ma-mannitol, $R$-raffinose, In-inositol, So-sorbitol, $A$-arabinose, and St-soluble starch. 
chlamydospores after another $45 \mathrm{hr}$ at room temperature on rice extract -Tween 80 agar. However, only three formed chlamydospores under the same conditions on media containing rice extract plus peptone and none did so on other media or when maintained continually at $37^{\circ} \mathrm{C}$.

The mean percentage of organisms with germ tubes formed by eight isolates in various aqueous carbohydrate media are shown in figure 1 . This was greatest for glucose, fructose, and galactose. Sucrose, xylose, maltose, trehalose, dextrin, and glycogen were moderately effective in inducing germ tube formation in $C$. albicans, while the rest were either ineffective or only very weakly effective. Germ tube formation was reduced as the concentration of glucose increased from 0.5 to $4 \%$.

Surprisingly, some organisms in all isolates formed germ tubes on all the agar media (table II) but only a small proportion did so on Noble agar and agarose. After another $48 \mathrm{hr}$ at $22^{\circ} \mathrm{C}$ none of the isolates had formed chlamydospores on agarose, only three of them did so on the rest of the media except when it included $0.1 \%$ glucose, in which case five of eight isolates formed chlamydospores.

\begin{tabular}{lll}
\hline Media & $\begin{array}{l}\text { No. with } \\
\text { Germ Tubes } \\
\text { after } 3 \mathrm{Hr} \\
\text { at } 37 \mathrm{C}\end{array}$ & $\begin{array}{l}\text { No. with } \\
\text { Chlamydospores } \\
\text { after Another } \\
45 \text { Hrat } 22 \mathrm{C}\end{array}$ \\
\hline $0.5 \%$ glucose in $2 \%$ agar & 8 & 3 \\
$0.1 \%$ glucose in $2 \%$ agar & 8 & 5 \\
$2 \%$ Difco agar & 8 & 3 \\
$2 \%$ Davis agar & 8 & 3 \\
$2 \%$ Ion agar no. 2 & 8 & 3 \\
$2 \%$ Noble agar & 81 & 3 \\
$2 \%$ Agarose & $8^{2}$ & - \\
\hline
\end{tabular}

Table II Formation of germ tubes and chlamydospores by eight isolates of Candida albicans on various agar media

${ }^{1}$ Very small percentage of organisms formed germ tubes.

${ }^{2}$ Only occasional organisms formed germ tubes.

Of the 250 isolates of yeasts tested, all 140 isolates of $C$. albicans but none of the 110 isolates belonging to other species, formed germ tubes within three hr at $37^{\circ} \mathrm{C}$ both on rice extract -tween 80 medium and on $0.1 \%$ glucose agar. A large proportion of the organisms of each isolate of C. albicans did so in each preparation (fig 2). After another $45 \mathrm{hr}$ at $22^{\circ} \mathrm{C}, 131$ isolates of $C$. albicans had formed chlamydospores on rice extract -Tween 80 medium. While 135 isolates did so on rice extract -Tween 80 medium kept continuously at $22^{\circ} \mathrm{C}, 130$ formed chlamydospores on $0.1 \%$ glucose agar kept for three $\mathrm{hr}$ at $37^{\circ} \mathrm{C}$ and then $45 \mathrm{hr}$ at $22^{\circ} \mathrm{C}$ (fig 3). However, all the isolates of $C$. albicans grown on $0.1 \%$ glucose agar formed pseudohyphae with

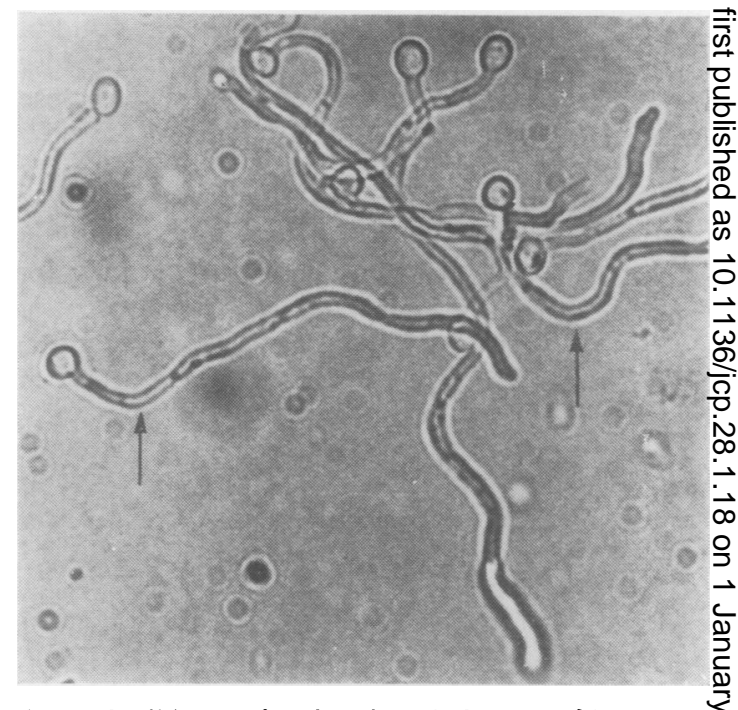

Fig 2 C.albicans after three hr at $37^{\circ} \mathrm{Con} 0 \cdot 1 \%$ glucose agar showing the formation of germ tubes (arrows) $\vec{\theta}$ The refractile dots are hubbles in the medium. $\times 800 \mathrm{G}$

characteristic clusters of blastospores distributed along the course of each pseudohypha (fig 4).

All the isolates of $C$. tropicalis formed long, branched, thin pseudomycelia with sparse laterale blastospores (fig 5) in all three types of preparation. $\overrightarrow{0}$ Whereas all the isolates of $C$. pseudotropicalis formed 3

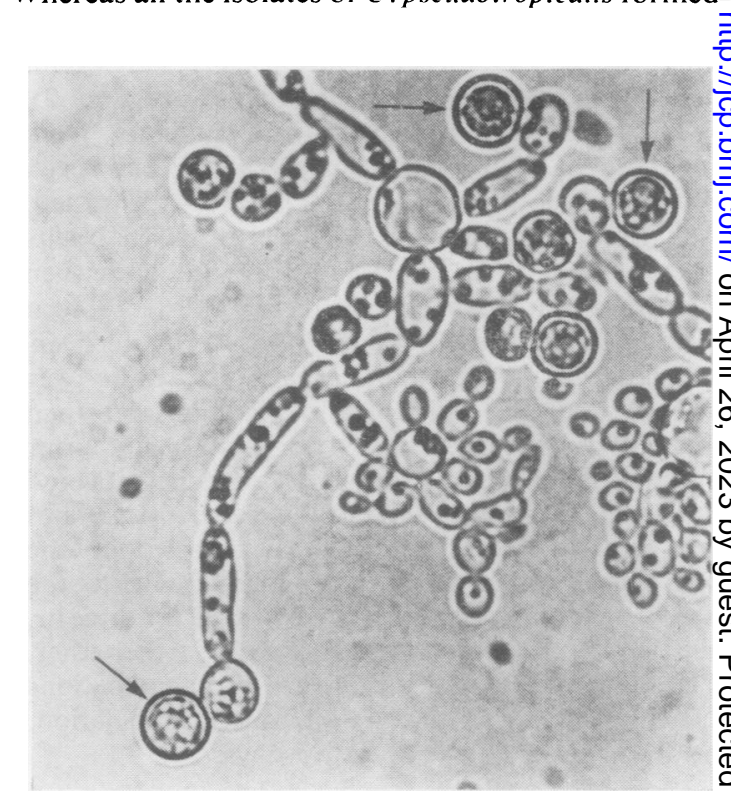

Fig 3 C. albicans after three $\mathrm{hr}$ at $37^{\circ} \mathrm{C}$ and then $45 \mathrm{hr}$ at $22{ }^{\circ} \mathrm{C}$ on $0.1 \%$ glucose agar showing pseudomycelium with chlamydospores (arrou's). $\quad 1000$ 


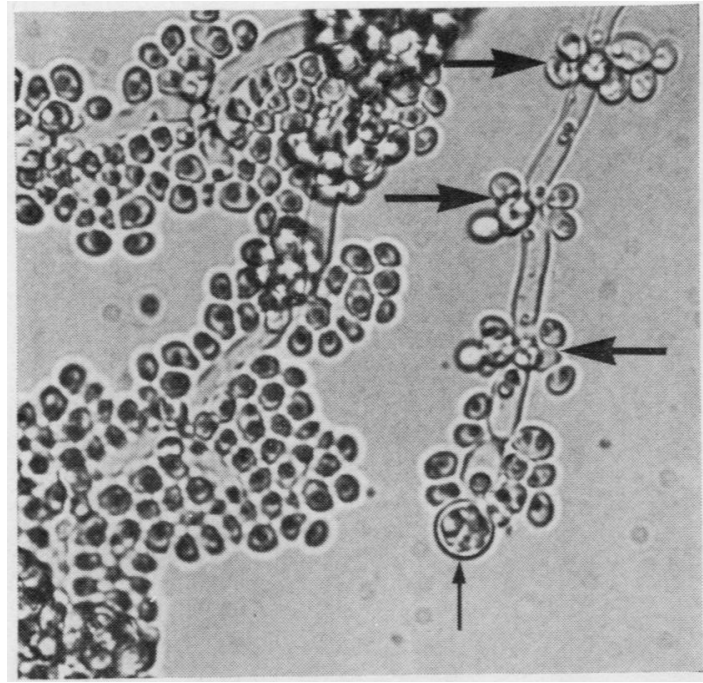

Fig 4 Pseudohyphae C. albicans on $0 \cdot 1 \%$ glucose agar showing clusters of blastospores (large arrows) and a terminal chlamydospore (small arrow). $\times 800$

pseudohyphae consisting of lines of spindle cells with similar elongated cells lying parallel to and alongside them (fig 6), the isolates of $C$. krusei all formed pseudohyphae with short lateral branches which had small terminal clusters of elongated blastospores with rounded ends giving them a 'match-stick' appearance (fig 7).

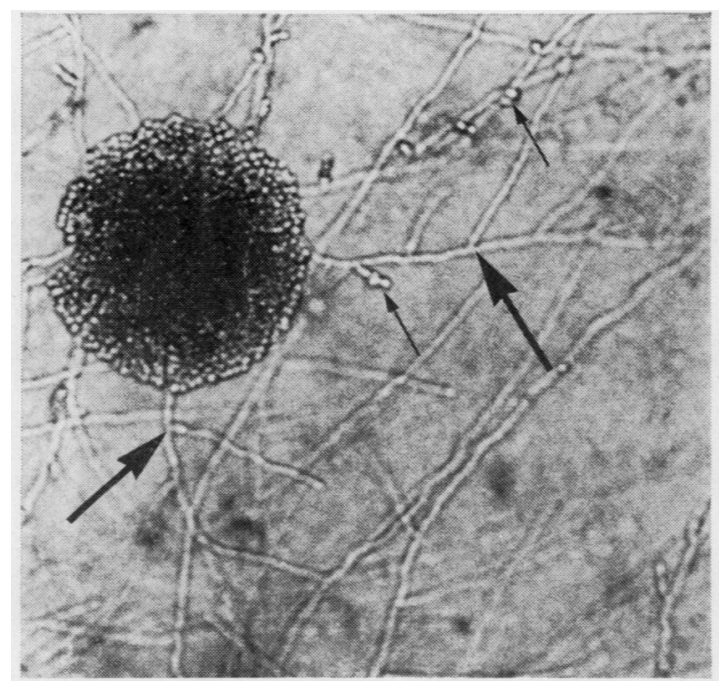

Fig 5 Long, branched, thin pseudomycelia (large arrows) of C. tropicalis on $0 \cdot 1 \%$ glucose agar. Blastospores (small arrows) are infrequent. $\times 500$

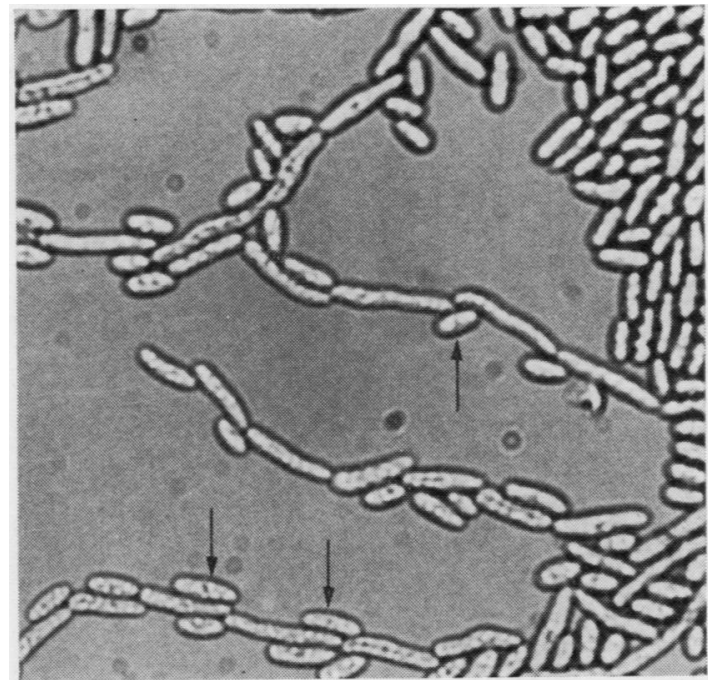

Fig 6 Pseudohyphae of C. pseudotrcpicalis on $0 \cdot 1 \%$ glucose agar consist of lines of elongated cells with ovoid blastospores (arrows) lying alongside. $\times 800$

Of the 33 isolates of $C$. parapsilosis, $29(87.9 \%)$ formed a typical spidery, branched, tree-like mycelium radiating from each colony on rice extract -Tween 80 agar when kept continuously at room temperature (fig 8), $25(75.8 \%)$ did so on the same medium when kept at $37^{\circ} \mathrm{C}$ for three hr and then at room temperature for $45 \mathrm{hr}$, but the other isolates

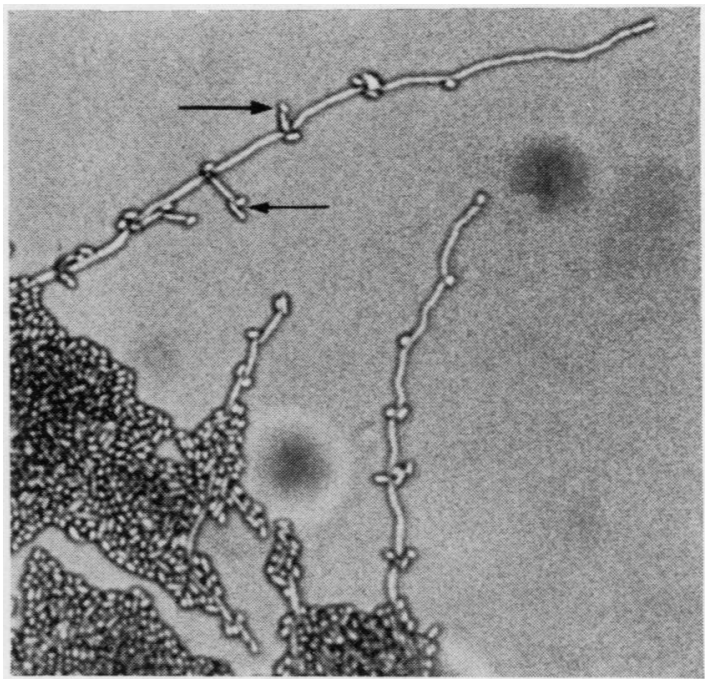

Fig 7 Pseudohyphae of C. krusei on $0 \cdot 1 \%$ glucose agar. showing short lateral branches with single small clusters of terminal blastospores (arrows). $\times 500$ 


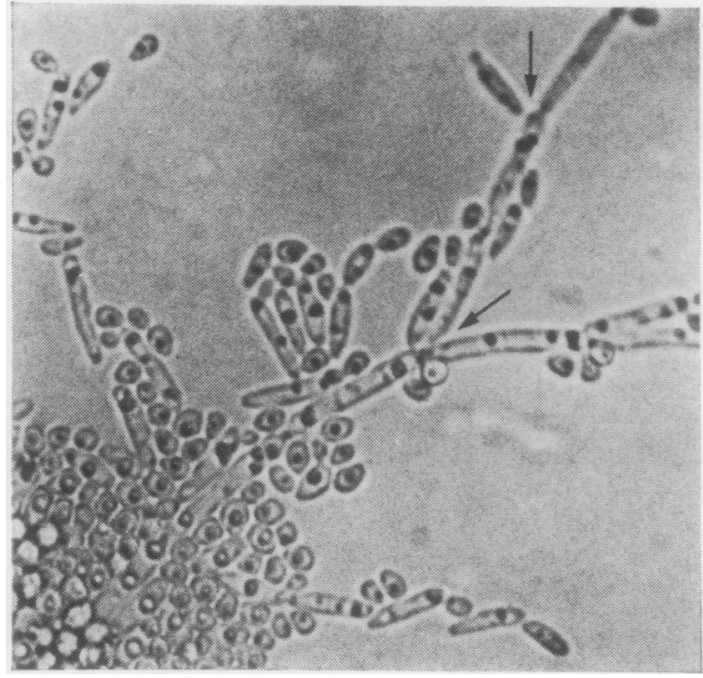

Fig 8

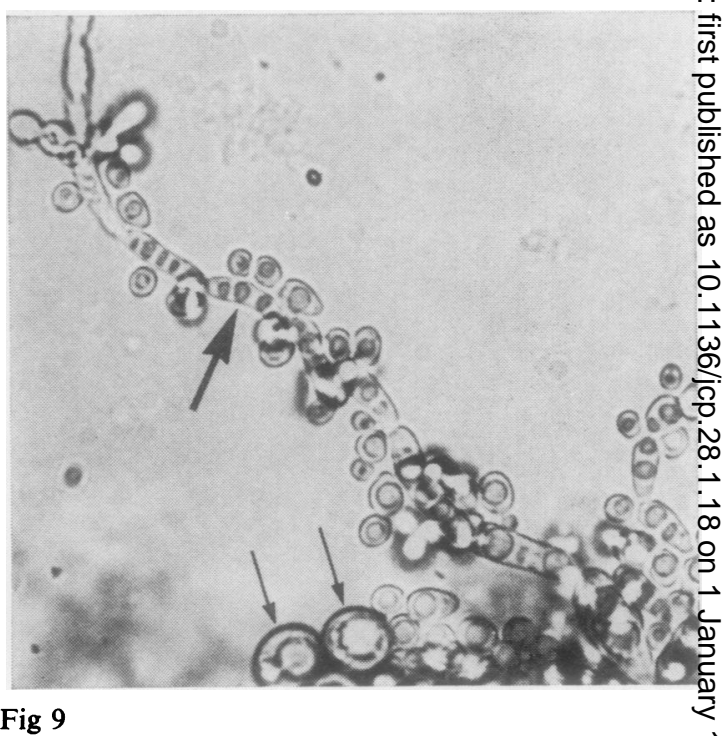

Fig 9

Fig 8 The common spidery, branched, tree-like mycelium (arrows) of C. parapsilosis on $0 \cdot 1 \%$ glucose agar. $\times 800$

Fig 9 The less common giant hypha (large arrow) and associated large cell types (small arrows) of C. parapsilosis on $0.1 \%$ glucose agar. $\times 800$

in both cases formed short unbranched pseudohyphae which were indistinguishable from those of C. guilliermondii. However, on $\mathbf{0} \cdot 1 \%$ glucose agar, $31(93.9 \%)$ isolates formed a typical spidery

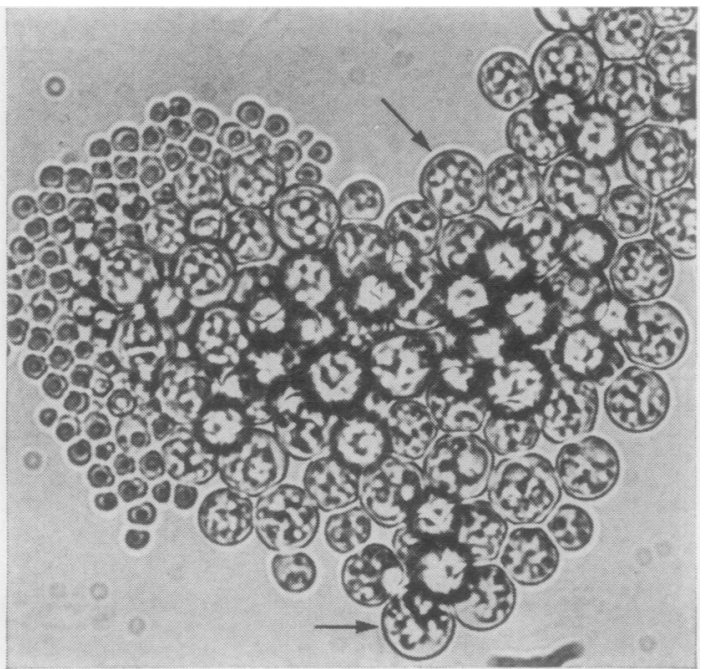

Fig 10 mycelium, and nine of these also formed numerou多 large spherical cells containing one or severa $\$$ refractile bodies, and giant hyphae (fig 9). Of thet remaining two isolates, one formed small colonie

Fig 10 An uncommon variant of C. parapsilosis on $0.1 \%$ glucose agar shows a small colony consisting mainly of large cell types (arrows) each containing several refractile bodies. $\times 800$

Fig 11 C. guilliermondii on $0 \cdot 1 \%$ glucose agar showing a short unbranched pseudohypha (arrow). $\times 800$ 


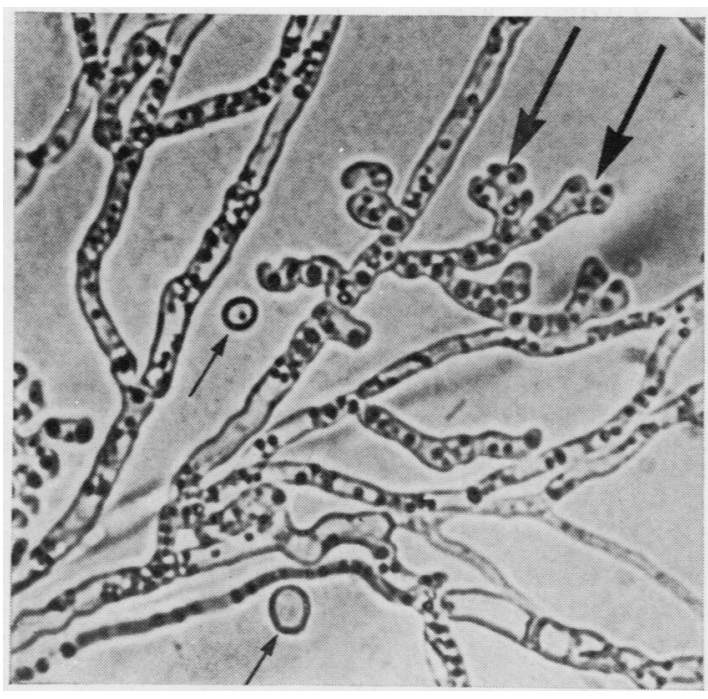

Fig 12 Pseudohyphae of T. cutaneum on $0.1 \%$ glucose agar showing arthrospores (large arrows) but few yeasts (small arrows). $\times 800$

consisting mainly of the larger organisms (fig 10) some with a few short pseudohyphae while the other formed only occasional short pseudohyphae.

All three isolates of $C$. guilliermondii formed short unbranched pseudohyphae when cultured either on rice extract -Tween 80 medium at room temperature or on $0.1 \%$ glucose agar (fig 11 ), but when the rice extract -Tween 80 medium was subjected to an initial three-hr incubation at $37^{\circ} \mathrm{C}$, two isolates failed to form pseudohyphae even after seven days at room temperature.

With the isolates of Trichosporon, all formed pseudohyphae, arthrospores, and a few yeasts on all the three media (fig 12), but none of the isolates of the Cryptococcus species, of Torulopsis glabrata, or of Saccharomyces cerevisae formed pseudohyphae. However, the smaller size of the blastospores of Torulopsis glabrata was clearly evident and a capsular halo was apparent around the blastospores of Cryptococcus neoformans.

While three isolates of $C$. guilliermondii, two of C. parapsilosis (which formed short and scanty pseudohyphae), and four of C. krusei did not form characteristic pseudohyphae within $48 \mathrm{hr}$, all did so by 72 hours. The daily examination of plates beyond $72 \mathrm{hr}$ did not reveal much improvement in morphological detail, except that the number of chlamydospores was increased in some isolates of C. albicans on rice extract -Tween 80 media.

With the $0 \cdot 1 \%$ glucose agar, prolonged growth sometimes resulted in a masking of the pseudohyphae by yeast forms.

\section{Discussion}

These observations indicate that virtually all pathogenic yeasts which form pseudohyphae can be identified within $48 \mathrm{hr}$ by direct microscopic examination of one culture grown on a single medium, $0 \cdot 1 \%$ glucose agar.

After three $\mathrm{hr}$ at $37^{\circ} \mathrm{C}$ all isolates of $C$. albicans exhibited germ tube formation which unequivocally identified that species. This was confirmed after a further $45 \mathrm{hr}$ at room temperature by their formation of a typical pseudomycelium with clusters of lateral blastospores, and in the majority (92.9\%) of isolates, terminal chlamydospores as well. These pseudomycelial features were similar to those seen on rice extract -Tween 80 agar maintained at room temperature, the method which is more commonly used to demonstrate them. While slightly fewer $(3.6 \%)$ isolates of $C$. albicans formed chlamydospores on $0.1 \%$ glucose agar than on rice extract -Tween 80 agar, the former seemed superior in inducing typical pseudomycelial morphology. For example, slightly more $(6 \%)$ isolates of $C$. parapsilosis developed appearances which distinguished them from C. guilliermondii on $0 \cdot 1 \%$ glucose agar.

Apart from our inability to distinguish one isolate of $C$. parapsilosis from three of $C$. guilliermondii, it was possible to identify correctly virtually all $(98.1 \%)$ of the yeasts which formed pseudomycelia using morphological criteria alone and without resort to the additional expense and complexity of germ tube, fermentation, and assimilation tests.

The ability of simple sugars like glucose, fructose, and galactose to facilitate germ tube formation supports the conclusion of McClary (1952) who showed that readily assimilable carbohydrate was necessary for filament formation by $C$. albicans. That they were most effective at low concentrations is consistent with the demonstration by Nickerson and Mankowski (1953) that in higher concentrations glucose tends to maintain the yeast phase.

Our observations that germ tube formation by C. albicans can occur on agar and even distilled water (Joshi et al, 1973) indicate that specific inducers of germ tube formation, such as were thought to exist in human (Taschdjian et al, 1960) and sheep (Dolan and Ihrke, 1971) serum, are unlikely to exist. It is more likely that a number of factors such as a warm temperature $\left(37^{\circ} \mathrm{C}\right)$, small inoculum size (Joshi et al, 1973), microaerobic conditions (Joshi and Gavin, 1974), and a small concentration of simple carbohydrate facilitate, but are not essential for this yeast mycelian transformation. 
The support of the Medical Research Council of New Zealand and the assistance of Mr J. Poon and Miss R. M. Griffiths are gratefully acknowledged. The senior author was supported by a Commonwealth medical fellowship.

\section{References}

Dolan, C. T. (1971). A practical approach to identification of yeastlike organisms. Amer. J. clin. Path., 55, 580-590.

Dolan, C. T., and Ihrke, D. M. (1971). Further studies of the germtube test for Candida albicans identification. Amer. J. clin. Path., 55, 733-734.

Joshi, K. R., Bremner, D. A., Gavin, J. B., Herdson, P. B., and Parr,
D. A. (1973). The formation of germ tubes by Candida albicans in sheep serum and trypticase soya broth. Amer. J. clin. Path. 60, 839-842.

Joshi, K. R., and Gavin, J. B. (1974). A simple laboratory metho for the rapid identification of Candida albicans. Pathology, 6 을 231-233.

Joshi, K. R., Gavin, J. B., and Bremner, D. A. (1973). The formatio of germ tubes by Candida albicans in various peptone media Sabouraudia, 11, 259-262.

McClary, D. O. (1952). Factors affecting the morphology of Candides albicans. Ann. Mo. bot. Gdn, 39, 137-164.

Nickerson, W. J., and Mankowski, Z. (1953). Role of nutrition in the maintenance of the yeast shape in Candida. Amer. J. Bot., 40, 584-592.

Taschdjian, C. L., Burchall, J. J., and Kozinn, P. J. (1960). Rapi@ identification of Candida albicans by filamentation on seruriक and serum substitutes. Amer. J. Dis. Child., 99 212-215. 